\title{
Early management of COPD: where are we now and where do we go from here? A Delphi consensus project
}

This article was published in the following Dove Press journal: International Journal of COPD

Fabiano Di Marco,' Piero Balbo, ${ }^{2}$ Francesco de Blasio, ${ }^{3}$ Vittorio Cardaci, ${ }^{4}$ Nunzio Crimi, ${ }^{5}$ Giuseppe Girbino, ${ }^{6}$ Girolamo Pelaia, ${ }^{7}$ Pietro Pirina, ${ }^{8}$ Pietro Roversi, ${ }^{9}$ Pierachille Santus, ${ }^{10,11}$ Nicola Scichilone, ${ }^{12}$ Alessandro Vatrella, ${ }^{13}$ Patrizio Pasqualetti, ${ }^{14}$ Mauro Carone ${ }^{15}$

'Department of Health Sciences, University of Milan, Respiratory Unit, Papa Giovanni XXIII Hospital, Bergamo, Italy; ${ }^{2} \mathrm{SC}$ Malattie dell'Apparato Respiratorio, AOU Maggiore della Carità, Novara, Italy; ${ }^{3}$ Respiratory Medicine and Pulmonary Rehabilitation Section, Clinic Center S.p.A. Private Hospital, Department of Medicine and Health Sciences "V Tiberio", University of Molise, Campobasso, Italy; ${ }^{4}$ Unit of Pulmonary Rehabilitation, IRCCS "San Raffaele Pisana", Rome, Italy: "Unità Operativa Complessa di Pneumologia e Allergologia, Policlinico Rodolico Vittorio Emanuele, Università di Catania, Catania, Italy; ${ }^{6}$ Dipartimento di Scienze Biomediche, Odontoiatriche e delle Immagini Morfologiche e Funzionali (BIOMORF), Università degli Studi di Messina, Messina, Italy; ${ }^{7}$ Department of Medical and Surgical Sciences, Unit of Respiratory Diseases, University Magna Graecia of Catanzaro, Catanzaro, Italy; ${ }^{8}$ Respiratory Unit, AOU Sassari, Sassari, Italy; ${ }^{9}$ Azienda Ospedaliera Universitaria, Policlinico Modena, Modena, Italy; ${ }^{10}$ Department of Biomedical and Clinical Sciences, University of Milan, Milan, Italy; "Division of Respiratory Diseases "L. Sacco" Hospital, ASST Fatebenefratelli Sacco, Milan, Italy; ${ }^{12}$ Dipartimento Biomedico di Medicina Interna e Specialistica (DIBIMIS), University of Palermo, Palermo, Italy; ${ }^{13}$ Department of Medicine, Surgery and Dentistry "Scuola Medica Salernitana", University of Salerno, Salerno, Italy; ${ }^{14}$ Fondazione Fatebenefratelli per la Ricerca e la Formazion Sanitaria e Sociale, Rome, Italy; ${ }^{15}$ Istituti Clinic Scientifici Maugeri, IRCCS di Cassano delle Murge, Cassano delle Murge (BA), Italy

Correspondence: Fabiano Di Marco Department of Health Sciences, University of Milan, Respiratory Unit, Papa Giovanni XXIII Hospital, Piazza OMS I, 24127 Bergamo, Italy Tel +390352673444

Email fabiano.dimarco@unimi.it
Purpose: There is a lack of consensus on the most appropriate early diagnostic strategy, criteria for early access to treatment and follow-up approach for patients with COPD.

Materials and methods: A Delphi consensus project investigated the early management of COPD. We formulated two questionnaires for completion by pneumologists in Italy.

Results: A total of 207 specialists completed questionnaire 1 and 184 of them questionnaire 2, between November 2016 and October 2017. Early diagnosis of COPD was considered uncommon for $93.2 \%$ of the expert panel. Regardless of the definition of "early diagnosis" - a diagnosis made before the clinical manifestation of the disease for most responders $(60.4 \%)$ - experts were confident of the positive effects of early disease management, which they consider is effective in modifying the natural history of the disease. Lack of awareness of the disease was considered the first limiting factor to early COPD management for $78 \%$ of respondents. The most effective steps to reduce functional decline were considered to be smoking cessation, followed by long-acting $\beta 2$-agonist (LABA)/long-acting muscarinic antagonist (LAMA), LAMA, LABA, and finally inhaled corticosteroid/LABA ( $P<0.01$ for each paired comparison). Specialists considered it "inappropriate" for general practitioners to perform both the early diagnosis and therapy of COPD without the involvement of a specialist.

Conclusion: Early management of COPD is uncommon, and although data on the effects of early disease management on long-term outcomes are limited, Italian experts are confident of the clinical efficacy of this approach.

Keywords: Italy, bronchodilator therapy, respiratory symptoms, dyspnea

\section{Introduction}

COPD is defined as a "preventable and treatable disease, which is characterised by persistent airflow limitation that is usually progressive and associated with an enhanced chronic inflammatory response in the airways and the lung to noxious particles or gases." It is a major cause of morbidity and mortality worldwide. ${ }^{1}$ Total deaths from COPD are projected to increase by $>30 \%$ in the next 10 years, and according to The Global Burden of Disease Study, in 2020 COPD will be the third leading cause of death worldwide. ${ }^{2}$ Previously, COPD was more common in men, but because of increased tobacco use among women in high-income countries and the higher risk of exposure to indoor air pollution in low-income countries, the disease now affects men and women almost equally. In the International Burden of Obstructive Lung Diseases (BOLD) survey, the prevalence of spirometrically confirmed COPD in adults was estimated to be $10 \%{ }^{3}$

In the majority of patients, COPD is a progressive condition, with deteriorating lung function over time in addition to the natural decline in pulmonary function that occurs 
with increasing age. This debilitating and chronic disease carries a significant economic burden on both individuals and society, with direct healthcare costs due primarily to exacerbation-related hospitalizations and indirect costs due to loss of productivity. ${ }^{1,4}$ The prognosis for COPD patients depends on the severity of disease, those with severe disease are more prone to severe exacerbations, hospitalizations, respiratory failure, and death. Patients with milder disease are at less risk of the above but have an increased risk of disease progression. ${ }^{5}$ Moreover, patients with mild COPD have a reduced quality of life/exercise tolerance and increased healthcare resource utilization.

Early intervention in COPD, with smoking cessation, pharmacological therapy, and non-pharmacological treatment options such as rehabilitation, can reduce decline in lung function and the risk of exacerbations and improve quality of life, as demonstrated by a recent paper which showed the efficacy of the long-acting muscarinic antagonist (LAMA), tiotropium, on $\mathrm{FEV}_{1}$ decline in patients with early stage disease. ${ }^{5,6}$ Unfortunately, despite the rising prevalence and substantial socioeconomic impact of COPD, misdiagnosis and underdiagnosis continue to be a central problem in the management of this disease. Generally, many people with COPD, especially those with mild and moderate disease, remain underrecognized, underdiagnosed, and undertreated, even though it is now considered to be treatable. ${ }^{7,8}$ Undiagnosed early stage COPD, particularly in symptomatic patients, is therefore likely to progress to more severe stages of the disease.

Consensus group methods such the Delphi method have been used successfully in medicine to synthesize expert opinion when GOLD standard evidence is not available. ${ }^{9,10}$ We conducted a Delphi consensus project to investigate the opinions on the early management of COPD patients - needs, approach to diagnosis and treatment, as well as suggestions on how to improve the early management of COPD.

\section{Materials and methods}

The Delphi technique is a validated process to develop consensus and make group-based decisions. ${ }^{11,12}$ Our study was conducted in four phases: 1) development of the survey questionnaire by the scientific committee; 2) selection of the expert panel; 3) completion of the online survey in two rounds; and 4) analysis of results and discussion of conclusions at an onsite meeting with the scientific committee.

\section{Delphi process}

The study was undertaken between November 2016 and September 2017. An advisory board (comprised 13 specialists from Italian universities and public hospitals) reviewed the medical literature on the early management of COPD and developed a questionnaire (Q1) (Supplementary material) including a set of seven demographic and organizational items and a second set of 27 scientific items focusing on epidemiological, diagnostic, and therapeutic topics. Questionnaire Q1 was administered, according to the Delphi method, to an expert panel comprising pulmonologists from the Italian healthcare system recommended by the scientific committee according to the geographical area. For some items participants expressed their opinion on a Likert scale between 0 and 5 , while for other items they ordered a set of options according to relevance matching their clinical experience. They also answered open questions. After the ratings from the first round were statistically analyzed, a second questionnaire (Q2) was drawn up and sent to the same professionals who responded to Q1 (Supplementary material). Q2, which included 22 items, was intended to better focus on some aspects and to solve certain ambiguities that emerged from Q1.

\section{Research ethics, confidentially, informed consent, and data protection}

Our Delphi study conformed to general ethical requirements aiming to assure "rigor, respect, and responsibility" in the conduct of research projects. The study as such was exempt from the need to obtain formal ethical board approval. Rights involved in the research study were explained at the outset, and by returning the questionnaires, the participants gave their consent to take part in the study. These measures support the ethical principles of respect and the right of self-determination and of obtaining an informed consent. No personal information was collected, and survey responses were collated anonymously. All responses received in the study were kept confidential, and identities of individual participants were not divulged. Survey responses were collected online using a secure Internet server and retained for the duration of the study.

\section{Statistical analyses}

To assess the agreement among the experts, the Delphi method uses a scale from 1 (maximal disagreement) to 9 (maximal agreement), with 5 corresponding to a neutral opinion about a given item. Thus, scores given by experts are statistically elaborated to obtain an appropriate "index of consensus." Inter-percentile Range Adjusted for Symmetry (IPRAS) scores were employed as indicators of the extent of agreement for each item. Using the inter-percentile range/ IPRAS computation, each statement can be classified with the appropriateness of a given diagnostic/therapeutic strategy in 
the following categories: appropriate (panel median of 7-9, without disagreement), uncertain (panel median of 4-6 or any median with disagreement), inappropriate (panel median of 1-3, without disagreement). When ranked in order of importance - 1 was an indicator of the most inappropriate/ irrelevant and 5 the most appropriate/relevant. Total scores indicate experts' level of preference with only those reaching $50 \%$ (of maximum) considered and reported. A two-sided significance level $\alpha$ of 0.05 was defined (mean \pm SD). As a general rule, non-parametric tests were applied to assess the differences between groups (Kruskal-Wallis and Mann-Whitney) and between items (Friedman and Wilcoxon). Bonferroni adjustment was carried out for multiple comparisons.

\section{Results}

The scientific committee recommended that Q1 was sent to 515 pneumologists and allergists working in the Italian healthcare system. The expert panel was representative of the geographic distribution of the hospital and/or university respiratory units in Italy. Feedback was received from 207 clinicians (40\% of those initially approached) with a geographical distribution as follows: North (39.1\%), Central (29.9\%), and South (30.9\%). Q2 was dispatched to all those who had previously replied to Q1 (207 experts), and replies were received from 184 (90\%). Most clinicians participating in the Delphi study were specialist pneumologists (92.8\%).

The average age of all the 207 respondents of Q1 was $53.2 \pm 9.2$ years. Fifty-two were women $(25 \%)$ and 155 men (75\%). In line with the demographics of medical doctors in Italy, there are more male doctors than female doctors, and female doctors tend to be younger than male doctors (47.4 \pm 9.7 and $55.1 \pm 8.1$ years, respectively). About $21 \%$ of the respondents work in respiratory centers with beds reserved for rehabilitation, with spirometers available in $99 \%$ of cases. Diffusing capacity of the lungs for carbon monoxide measurement was available in $90 \%$, body plethysmograph in $87 \%$, dosimeter for methacholine in $80 \%$, and cardiopulmonary exercise test in $63 \%$. Waiting times for a spirometry was estimated to be $<30$ days for $56 \%$ of respondents, between 30 and 60 days for $30 \%$, and $>60$ days for the remaining $14 \%$. On average, $62 \%$ of patients were referred to specialists by their general practitioners (GPs) and the remaining 38\% referred themselves.

\section{Meaning and importance of "early diagnosis" of COPD}

An "early diagnosis" of COPD was considered to be a diagnosis made before clinical manifestation of the disease by the majority of responders $(60.4 \%)$ (ie, primary prevention); a diagnosis when COPD is mild (secondary prevention) for $33.8 \%$ of responders. Only $5.8 \%$ of the responders believe that early diagnosis is an approach aimed at reducing the complications of the disease (ie, tertiary prevention). As a general rule, responders were confident of the positive effect of early management of the disease, with a high level of consensus on the question "does an early diagnosis affect the natural history of the disease?" (median of 8.0/9.0 with an interquartile range [IQR] of 7-9, Figure 1). Furthermore, $95.7 \%$ of responders were convinced that early management of the disease can affect therapeutic success. Moreover, over $90 \%$ of the responders treat patients with mild obstruction (ie, $\mathrm{FEV}_{1}>80 \%$ ) in all cases $(20 \%)$ or in the presence of symptoms $(70 \%)$.

\section{Early diagnosis of COPD: fact or fiction?}

According to those who responded, early diagnosis of COPD is uncommon with only $6.8 \%$ of the expert panel stating that it occurs in real-life clinical practice. According to the expert panel, factors limiting early diagnosis and treatment of COPD are (in order to importance): lack of awareness about the disease (78\% of respondents), "lack of interest" by GPs (41\%), not a priority disease for GPs even if they understand its importance (48\%), and difficulties in performing spirometry (57\%) (Figure 2). In total, 12\% of the responders replied that on average, new patients report that they have symptoms for $<1$ year. Importantly, experts replied that only $15 \%$ of patients received a diagnosis when their disease was still mild according to spirometry (GOLD 1) and 15.8\% were diagnosed according to symptoms/ exacerbations (GOLD 1).

\section{Early diagnosis/screening: who should be evaluated?}

In reply to the question which categories of smokers should have an early diagnosis, the Expert Panel gave the following importance scores (possible range: $\min =1, \max =5$ ): heavy smokers, 4.2; smokers with comorbidities, 4.0; and young smokers, 3.8. Each pairwise Wilcoxon paired comparison (following a significant overall Friedman's test, $P<0.001$ ) resulted statistically significant (consistently, $P<0.020$ ).

\section{Treating patients with mild COPD: the pharmacological approach}

According to the expert panel, the role of patient preference in the choice of therapy is not affected by early diagnosis of the disease (4.0/5.0 in both cases, $P=0.136)$. The level of confidence in the different approaches used to reduce the functional decline in mild COPD were stopping smoking 


\begin{tabular}{|l|c|c|c|c|}
\hline \multicolumn{1}{|c|}{ Items } & Median & IQR & IPRAS & Assessment \\
\hline $\begin{array}{l}\text { "Early diagnosis" of COPD can change the } \\
\text { natural history of the disease }\end{array}$ & 8 & $7-9$ & 6.85 & Appropriate \\
\hline $\begin{array}{l}\text { Adequacy of tools to early detect COPD patients: } \\
\text { a. Questionnaires and/or risk cards during } \\
\text { visits to GP }\end{array}$ & 7 & $6-8$ & 6.1 & Appropriate \\
\hline $\begin{array}{l}\text { Adequacy of tools to early detect COPD patients: } \\
\text { b. Identification from the GP databases of } \\
\text { patients treated with bronchodilator drugs }\end{array}$ & 7 & $5-8$ & 5.35 & Appropriate \\
\hline $\begin{array}{l}\text { Adequacy of tools to early detect COPD patients: } \\
\text { c. Identification from the GP databases of patients } \\
\text { treated with cycles of systemic steroids }\end{array}$ & 6 & $5-8$ & 3.85 & Uncertain \\
\hline $\begin{array}{l}\text { Appropriateness of policies: } \\
\text { a. GPs must select the patients to be sent } \\
\text { to specialists }\end{array}$ & 8 & $7-9$ & 7.6 & Appropriate \\
\hline $\begin{array}{l}\text { Appropriateness of policies: } \\
\text { b. GPs must select the patients they will submit to } \\
\text { spirometry, and if pathological they will send } \\
\text { the patient to specialist }\end{array}$ & 6 & $4-8$ & 4.225 & Uncertain \\
\hline $\begin{array}{l}\text { Appropriateness of policies: } \\
\text { c. The GPs take care of both the diagnosis and } \\
\text { the phase of staging and therapy }\end{array}$ & 2 & $1-4$ & 6.85 & Inappropriate \\
\hline
\end{tabular}

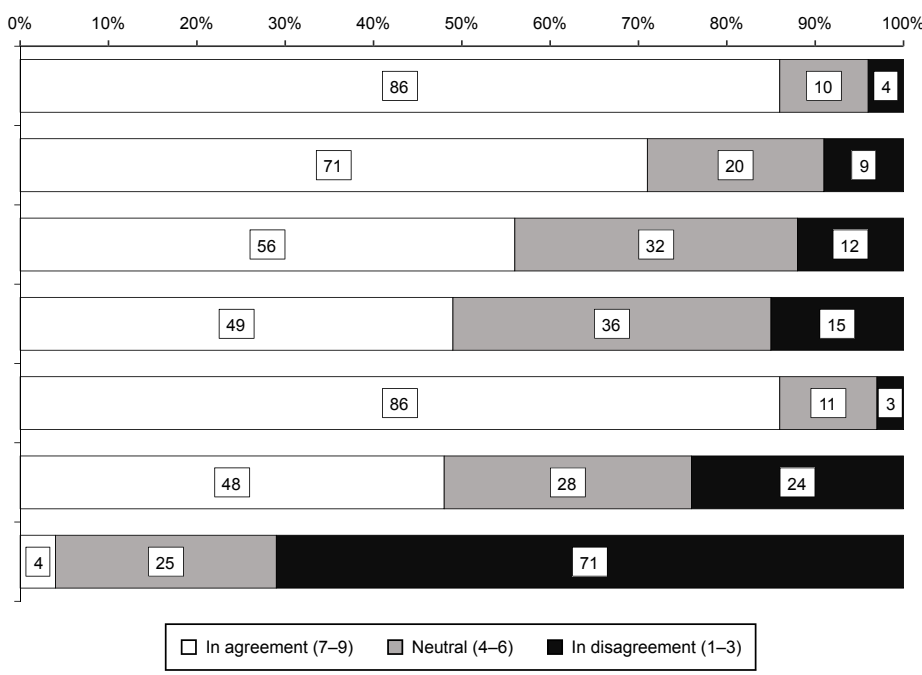

Figure I Level of consensus on the early management of COPD.

Abbreviations: GP, general practitioner; IPRAS, Inter-percentile Range Adjusted for Symmetry.

(highest score), followed by a LAMA plus long-acting betaagonist (LABA), a LAMA, a LABA, and finally inhaled corticosteroid (ICS) plus LABA $(P<0.01)$ for each paired comparison (Figure 3 ). In patients with $\mathrm{MRC} \geq 2$ dyspnea and a $\mathrm{FEV}_{1}$ between $50 \%$ and $80 \%$ (moderate obstruction), the level of consensus in different treatments in both younger and older patients is reported in Figure 4 (each paired comparison is significantly different, $P<0.001$ ). In terms of appropriateness, the order was 1) LABA/LAMA; 2) single bronchodilator; 3) ICS/LABA; 4) no treatment in both cases with age
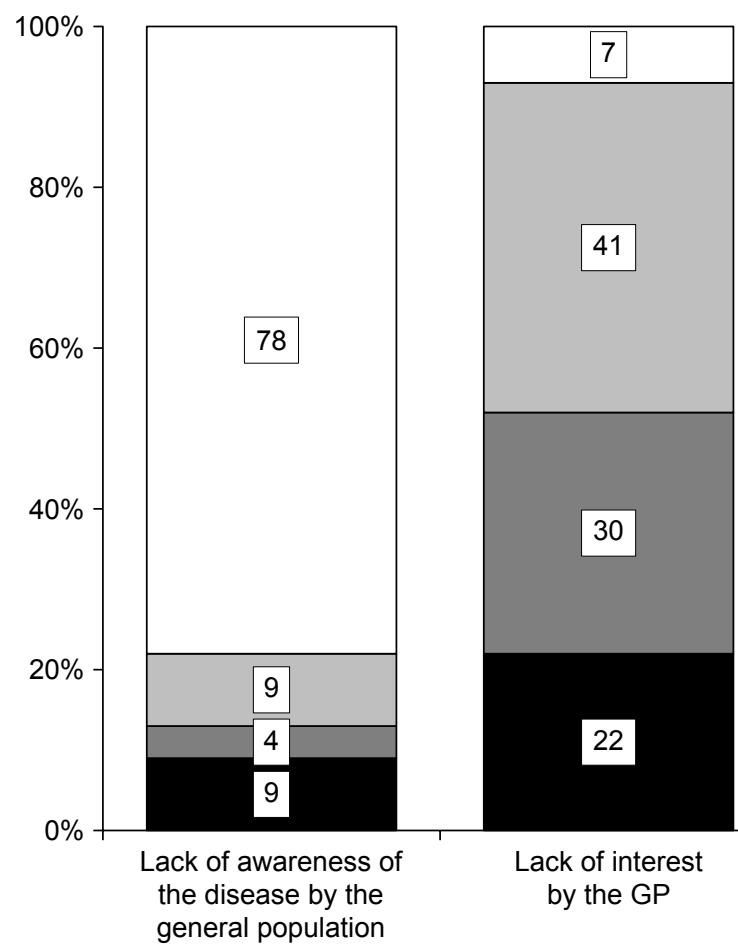

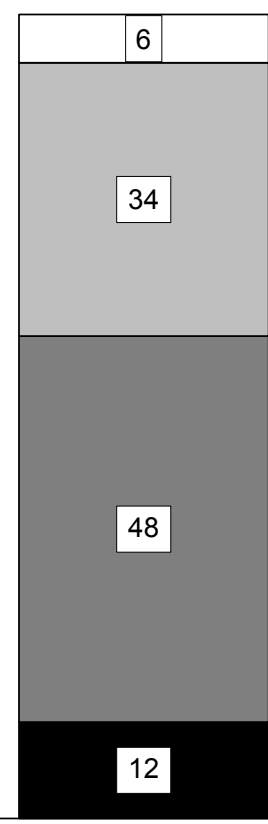

Presence of other priorities for the GP who knows anyway the importance of the disease

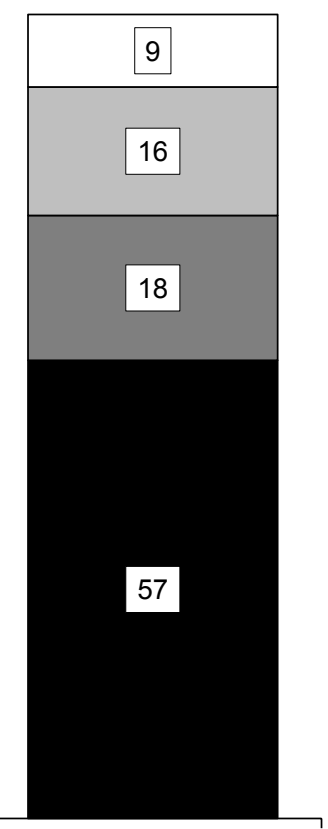

Difficulties of the GP to get a diagnosis

\section{$\square$ First $\square$ Second $\square$ Third $\square$ Fourth}

Figure 2 Relevance of factors limiting early diagnosis of COPD according to expert panel.

Note: First, second, third, and fourth refer to the rank order of the answers.

Abbreviation: GP, general practitioner. 


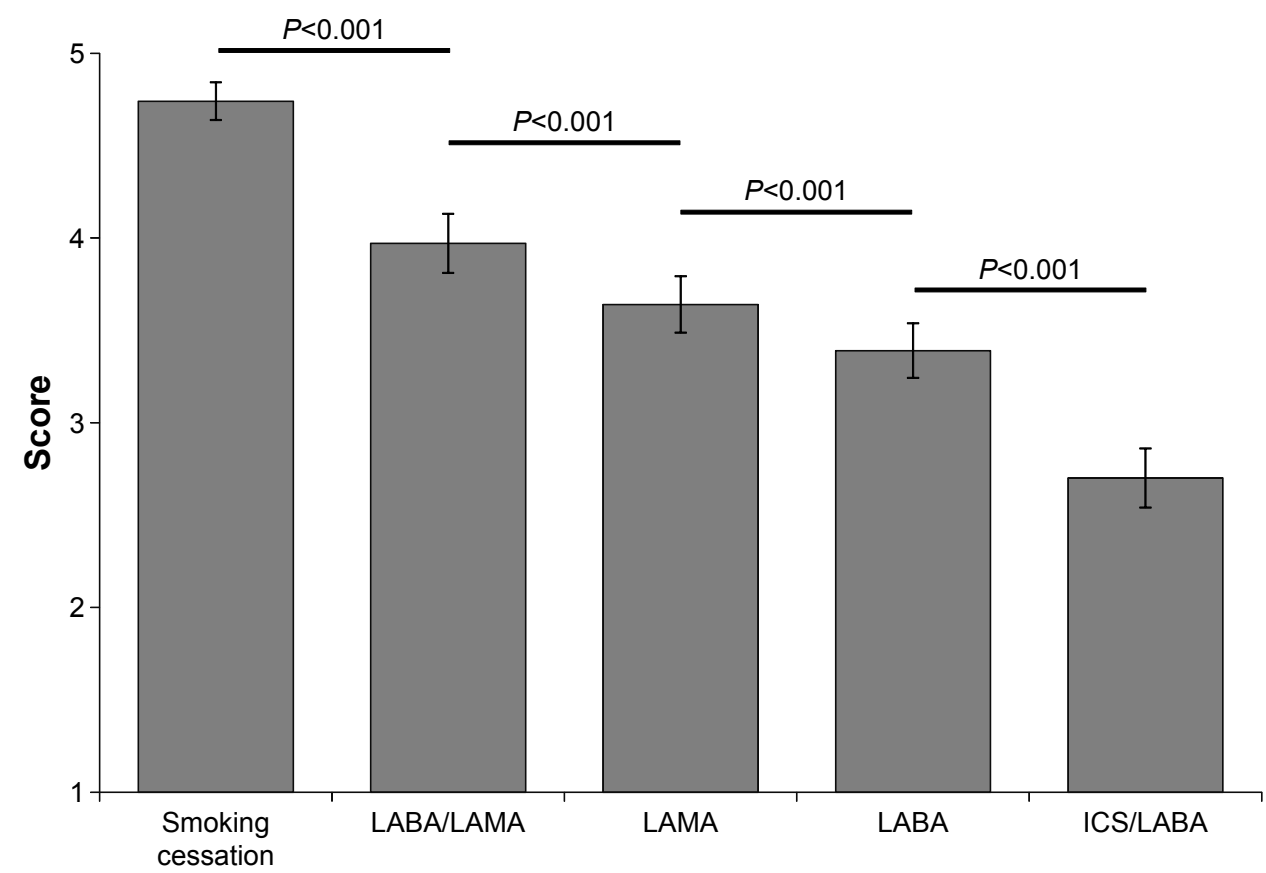

Figure 3 Level of confidence in different approaches used in the early management of COPD to reduce the functional decline. Note: Each pairwise comparison was significant $(P<0.001)$.

Abbreviations: ICS, inhaled corticosteroid; LABA, long-acting beta-agonist; LAMA, long-acting muscarinic antagonist.

having a significant effect $(P<0.001)$. The appropriateness of starting with a single bronchodilator (although lower than that of starting with LABA/LAMA) had a higher level of consensus when applied in young patients, whereas LABA/ LAMA was assigned a higher level of appropriateness for older patients (Figure 4).

\section{Improving early management of COPD patients}

Over $50 \%$ said that they would be available to promote/be involved in a specific campaign aimed at increasing the level of early management in COPD and over $30 \%$ would be available to take part in such an initiative organized by a scientific society.

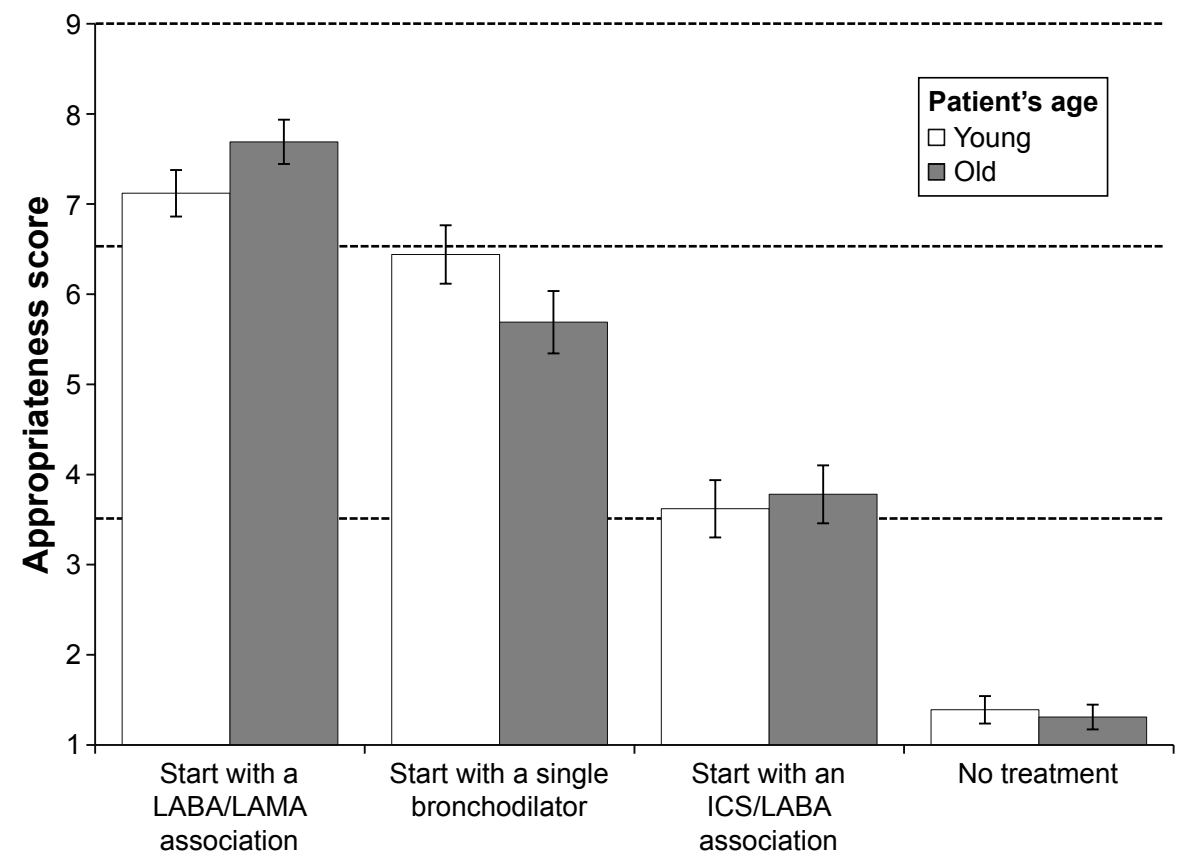

Figure 4 Level of consensus on different treatments in patients younger and older with moderate obstruction (mean $\pm 95 \% \mathrm{Cl}$ ). Abbreviations: ICS, inhaled corticosteroid; LABA, long-acting beta-agonist; LAMA, long-acting muscarinic antagonist. 
Subjects to be screened should be selected by GPs (approach considered "appropriate": median $=8, \mathrm{IQR}=7-9$ ), while experts are less certain about the role of GPs in spirometry (median $=6, \mathrm{IQR}=4-8$ ). The involvement of a specialist in the field was considered crucial and respondents considered it "inappropriate" for GPs to perform both diagnosis and therapy of these patients (median $=2$, IQR =3-4) without the involvement of a specialist (Figure 1). The tools considered "appropriate" to select subjects to be evaluated for early diagnosis are questionnaires carried out during clinical evaluation (median $=7, \mathrm{IQR}=6-8$ ) and analysis of the GP database to identify patients treated with bronchodilators ( median $=7, \mathrm{IQR}=5-8$ ). Experts were less sure about a selection based on the use of systemic steroids and/or antibiotics ( median $=6$, IQR $=5-8$ ). Experts considered that once early diagnosis was made, follow-up should be carried out by specialists rather than GPs (4.4 vs 2.8 in a $1-5$ scale, $P<0.001$, Figure 1).

\section{Discussion}

Our Delphi-based study focused on open issues on the optimal strategy for the therapeutic management of patients with early stage COPD. A two-round Delphi consensus explored the opinions of a large number of pneumologists in Italy on the early diagnosis and treatment of COPD. This is one of the few studies to involve such a large cohort of pneumologists (515 experts received the first questionnaire, with 207 replying). Other recently reported study involved up to a maximum of 200 experts in respiratory medcine. ${ }^{13-18}$

Results of our study show that the majority of experts agreed on most of the proposed items and replies were in-line with the GOLD 2017 recommendations. ${ }^{1}$ COPD is a progressive condition, and early diagnosis may allow a change in the natural history of COPD with significant savings both in terms of costs to health care systems as well as to patients. ${ }^{19}$

Smoking cessation is vital to modify the natural history of COPD ${ }^{20,21}$ Early pharmacological therapy has also been recognized as an important factor in slowing down the functional decline, reducing the exacerbations/long-term consequences, and improving the quality of life. ${ }^{22-26}$ Although it is generally accepted that pharmacological therapy should be considered a possible early intervention in COPD, the optimal maintenance therapy - single bronchodilator (short- or long-acting LAMA or LABA) vs LABA-LAMA vs ICS-LABA - is still being debated. ${ }^{27}$

Our panel of experts addressed these issues and reached a series of outcomes. First, they agreed that an early diagnosis must include primary and secondary prevention $(>95 \%$ of responders). They were confident that early management of COPD could affect its natural history and over $90 \%$ of panelists confirmed that starting long-acting bronchodilators in mildly obstructed both symptomatic and asymptomatic patients was appropriate. American College of Physicians, American College of Chest Physicians, American Thoracic Society, and European Respiratory Society guidelines state that available evidence is not sufficient to recommend the use of bronchodilators in asymptomatic individuals. ${ }^{28}$ The results of our Delphi consensus are in general agreement with international guidelines as the majority of specialists stated they would treat "mild" disease only in the presence of symptoms ( $70 \%)$ and $20 \%$ of them sustained that they would treat asymptomatic patients. Nevertheless, there is some evidence that mild/moderate obstruction of airflow can present without actual symptoms and a number of studies report a cohort of patients as COPD patients who have socalled silent obstruction in the absence of symptoms (chronic cough, phlegm, and/or dyspnea) but with airflow limitation on spirometric examinations. ${ }^{29-32}$ This is not a completely unexpected finding given that the severity of symptoms and airway obstruction are weakly correlated. ${ }^{33}$ It therefore follows that early intervention may delay or even avoid not just the manifestation of symptoms but also other clinical indicators, such as acute exacerbations, with their attendant long-term consequences. While there is some evidence to support this hypothesis, it needs to be evaluated in prospective clinical trials, as the impact of pharmacological therapy in comparison with smoking cessation is not yet known. ${ }^{34}$

Our results are similar to those reported by another group of Italian specialists in COPD. ${ }^{35}$ In our study, experts did not reach a consensus on the effectiveness of increasing the dosage of bronchodilators to better control COPD, but a substantial number considered this to be a fitting approach. In fact, in everyday life, a patient on monotherapy experiencing breathing difficulties will frequently increase the dosage of his/her bronchodilator in the hope of improving symptoms. ${ }^{35,36}$ Results of our study confirmed previous investigations and the majority of experts were in agreement that patients not fully controlled with a single bronchodilator should receive another bronchodilator preferably with a different mechanism of action. ${ }^{35}$ It is now well accepted that the combination of a LABA and LAMA is the most appropriate treatment for early COPD, especially in older patients $(P<0.001)$ (Figure 4). Using multiple drugs in combination has a number of important advantages including decreasing the possibility of adverse effects, simplifying treatment regimens, and increasing adherence to therapy. ${ }^{37}$ 
International guidelines (GOLD 2017, 2018) endorse the use of LABAs in combination with antimuscarinics if there is no adequate improvement in symptoms with monotherapy. ${ }^{1}$ Dual therapy such as fixed combinations of LABA and LAMA has been shown to play an important role in obtaining maximum bronchodilator effects. Results of clinical trials suggest that fixed dose combination bronchodilator therapy provides significantly greater improvements in lung function compared with monotherapy although the precise mechanism has yet to be fully elucidated..$^{35,38,39}$ It should also be noted that combination therapy is well tolerated in patients with moderate-to-severe COPD. ${ }^{1}$

Unfortunately, early diagnosis in real-life clinical practice is as yet uncommon not least because patients are referred to specialists when they have moderate to advanced disease. According to our group of experts, the main reason for this seems to a lack of awareness about the disease $(77 \%$ of responders). It is therefore vital to find strategies to increase patient and physician awareness about COPD, especially in heavy smokers (score 4.2/5 in our expert panel) or when more comorbidities are present (score 4/5). Moreover, even when an early diagnosis is made, non-adherence to medication regimens is a significant problem in the management of COPD. ${ }^{40}$ It is therefore vital, according to the panel, when faced with a situation where symptoms are not controlled, to first establish if the patient is actually taking the medication as prescribed before deciding to change to a different medication or to increase the dosage of an existing medication (median 7.5, IQR =7-8).

\section{Conclusion}

Early management of COPD is not common, and although there are limited data on the effects of early disease management on long-term outcomes, Italian experts are confident of the clinical efficacy of this approach. Smoking cessation should be the first step followed by pharmacological therapies. The expert panel was in agreement on the important role of fixed dosage LABA/LAMA on the natural history of the disease and in preventing/ameliorating functional decline. Finally, the expert panel considered that while GPs are crucial for early diagnosis, the role of specialist is vital in the early management of COPD patients.

The advantage of consensus panels in general and our Delphi study in particular is that they allow expert opinion on a wide variety of topics to be captured - in our case on the management of COPD. While results support the everyday decision-making process in the management of early COPD, they only mirror the Italian situation, and as such, we consider that a multinational survey is necessary to support the consensus scenario and to further investigate some of the issues not yet completely addressed by the current international guidelines.

\section{Acknowledgments}

This study was supported by an unrestricted grant from AstraZeneca. The funding source had no role in the study design, data collection and analysis, decision to publish, or preparation of manuscript. The authors would like to thank ThinkTank, Milan, for support in implementing the Delphi Methodology.

\section{Author contributions}

FDM and $\mathrm{MC}$ acted as manuscript coordinators and Patrizio Pasqualetti carried out the statistical analysis. All authors contributed to data analysis, drafting or revising the article, gave final approval of the version to be published, and agree to be accountable for all aspects of the work.

\section{Disclosure}

Dr. Di Marco has received honoraria for lectures at national and international meetings from Almirall, AstraZeneca, Boehringer Ingelheim, Chiesi Farmaceutici, Dompe, Guidotti/Malesci, GlaxoSmithKline, Menarini, Novartis, and Zambon. He has served as a consultant for AstraZeneca, Chiesi Farmaceutici, Novartis, and Zambon. He has received financial support for research from Novartis and Boehringer Ingelheim. Prof. Dr. de Blasio has served as a consultant for AstraZeneca, and Dr. Santus has served as a consultant for AstraZeneca, Boehringer Ingelheim, Zambon Italia, Guiodotti, GSK, and Chiesi Farmaceutici. The authors report no other conflicts of interest in this work.

\section{References}

1. GOLD [homepage on the Internet]. From the Global Strategy for the Diagnosis, Management and Prevention of COPD, Global Initiative for Chronic Obstructive Lung Disease (GOLD) 2017. Available from: http:// goldcopd.org. Accessed June 2018.

2. World Health Statistics; 2008. Available from: http://www.who.int/ whosis/whostat/EN_WHS08_Full.pdf. Accessed June 2018.

3. Buist AS, Vollmer WM, McBurnie MA. Worldwide burden of COPD in high- and low-income countries. Part I. The burden of obstructive lung disease (BOLD) initiative. Int J Tuberc Lung Dis. 2008; 12(7):703-708.

4. Anzueto A. Impact of exacerbations on COPD. Eur Respir Rev. 2010; 19(116):113-118.

5. Welte T, Vogelmeier C, Papi A. COPD: early diagnosis and treatment to slow disease progression. Int J Clin Pract. 2015;69(3):336-349.

6. Zhou Y, Zhong NS, Li X, et al. Tiotropium in early-stage chronic obstructive pulmonary disease. $N$ Engl J Med. 2017;377(10):923-935.

7. Decramer M, Miravitlles M, Price D, et al. New horizons in early stage COPD - improving knowledge, detection and treatment. Respir Med. 2011;105(11):1576-1587. 
8. British Lung Foundation [homepage on the Internet]. Invisible lives. Chronic obstructive lung disease (COPD) - finding the missing millions; 2010. Available from: http://www.lunguk.org. Accessed April 2013.

9. Murphy MK, Black NA, Lamping DL, et al. Consensus development methods, and their use in clinical guideline development. Health Technol Assess. 1998;2(3):1-88.

10. Fink A, Kosecoff J, Chassin M, Brook RH. Consensus methods: characteristics and guidelines for use. Am J Public Health. 1984;74(9): 979-983.

11. Linstone H, Turoff M, editors. The Delphi Method. Techniques and Applications. Reading, MA: Addison-Wesley Publishing Company; 1975:1-616.

12. Jones J, Hunter D. Consensus methods for medical and health services research. BMJ. 1995;311(7001):376-380.

13. Miravitlles M, Soler-Cataluña JJ, Alcázar B, Viejo JL, García-Río F. Factors affecting the selection of an inhaler device for COPD and the ideal device for different patient profiles. Results of EPOCA Delphi consensus. Pulm Pharmacol Ther. 2018;48:97-103.

14. Padrão E, Araújo D, Todo Bom A, et al. Asthma-COPD overlap: a Portuguese survey. Pulmonology. 2018;24(3):174-181.

15. Dapari R, Ismail H, Ismail R, Ismail NH. Application of fuzzy Delphi in the selection of COPD risk factors among steel industry workers. Tanaffos. 2017;16(1):46-52.

16. Hill AT, Haworth CS, Aliberti S, et al. Pulmonary exacerbation in adults with bronchiectasis: a consensus definition for clinical research. Eur Respir J. 2017;49(6):1700051.

17. Plaza V, Álvarez F, Calle M, et al. Consensus on the Asthma-COPD Overlap Syndrome (ACOS) Between the Spanish COPD Guidelines (GesEPOC) and the Spanish Guidelines on the Management of Asthma (GEMA). Arch Bronconeumol. 2017;53(8):443-449. English, Spanish.

18. Ninane V, Corhay JL, Germonpré P, et al. Inhaled treatment of COPD: a Delphi consensus statement. Int J Chron Obstruct Pulmon Dis. 2017;12:793-801.

19. Rhee CK, Kim K, Yoon HK, et al. Natural course of early COPD. Int J Chron Obstruct Pulmon Dis. 2017;12:663-668.

20. Fletcher $\mathrm{C}$, Peto R. The natural history of chronic airflow obstruction. Br Med J. 1977;1(6077):1645-1648.

21. Anthonisen NR, Skeans MA, Wise RA, et al; Lung Health Study Research Group. The effects of a smoking cessation intervention on 14.5-year mortality: a randomized clinical trial. Ann Intern Med. 2005; 142:233-239.

22. Soler-Cataluña JJ, Martínez-García MA, Román Sánchez P, Salcedo E, Navarro M, Ochando R. Severe acute exacerbations and mortality in patients with chronic obstructive pulmonary disease. Thorax. 2005; 60(11):925-931.

23. Donaldson GC, Seemungal TA, Bhowmik A, Wedzicha JA. Relationship between exacerbation frequency and lung function decline in chronic obstructive pulmonary disease. Thorax. 2002;57(10):847-852.

24. Decramer M, Dahl R, Kornmann O, Korn S, Lawrence D, McBryan D. Effects of long-acting bronchodilators in COPD patients according to COPD severity and ICS use. Respir Med. 2013;107(2): $223-232$.
25. Welte T, Chapman KR, Magnussen H, Miravitlles M. Current thinking and new paradigm for COPD. Respir Med. 2016;112:126-127.

26. Ariel A, Altraja A, Belevskiy A, et al. Inhaled therapies in patients with moderate COPD in clinical practice: current thinking. Int J Chron Obstruct Pulmon Dis. 2018;13:45-56.

27. Maltais F, Dennis N, Chan CK. Rationale for earlier treatment in COPD: a systematic review of published literature in mild-to-moderate COPD. COPD. 2013;10(1):79-103.

28. Qaseem A, Wilt TJ, Weinberger SE, et al; American College of Physicians; American College of Chest Physicians; American Thoracic Society; European Respiratory Society. Diagnosis and management of stable chronic obstructive pulmonary disease: a clinical practice guideline update from the American College of Physicians, American College of Chest Physicians, American Thoracic Society, and European Respiratory Society. Ann Intern Med. 2011;155(3):179-191.

29. van den Boom G, Rutten-van Mölken MP, Tirimanna PR, van Schayck CP, Folgering H, van Weel C. Association between healthrelated quality of life and consultation for respiratory symptoms: results from the DIMCA programme. Eur Respir J. 1998;11(1):67-72.

30. d'Andiran G, Schindler C, Leuenberger P. The absence of dyspnoea cough and wheezing. A reason for undiagnosed airflow obstruction? Swiss Med Wkly. 2006;136:425-433.

31. Shin C, Lee S, Abbott RD, et al. Respiratory symptoms and undiagnosed airflow obstruction in middle-aged adults: the Korean Health and Genome Study. Chest. 2004;126(4):1234-1240.

32. Lu M, Yao WZ, Zhong NS, et al. Asymptomatic patients of chronic obstructive pulmonary disease in China. Chin MedJ(Engl). 2010;123(12): 1494-1499.

33. Brand PL, Rijcken B, Schouten JP, Koëter GH, Weiss ST, Postma DS. Perception of airway obstruction in a random population sample. Relationship to airway hyperresponsiveness in the absence of respiratory symptoms. Am Rev Respir Dis. 1992;146(2):396-401.

34. van der Molen T, Willemse BW, Schokker S, Ten Hacken NH, Postma DS, Juniper EF. Development, validity and responsiveness of the Clinical COPD Questionnaire. Health Qual Life Outcomes. 2003; $1: 13$.

35. Cazzola M, Brusasco V, Centanni S, et al. Project PriMo: sharing principles and practices of bronchodilator therapy monitoring in COPD: a consensus initiative for optimizing therapeutic appropriateness among Italian specialists. Pulm Pharmacol Ther. 2013;26(2):218-228.

36. Cazzola M, Santus P, Castagna F, et al. Addition of an extra dose of salmeterol Diskus to conventional dose of salmeterol Diskus in patients with COPD. Respir Med. 2002;96(6):439-443.

37. Mak G, Hanania NA. New bronchodilators. Curr Opin Pharmacol. 2012;12(3):238-245.

38. Cazzola M, Tashkin DP. Combination of formoterol and tiotropium in the treatment of COPD: effects on lung function. COPD. 2009;6(5): 404-415.

39. Cazzola M, Molimard M. The scientific rationale for combining longacting beta2-agonists and muscarinic antagonists in COPD. Pulm Pharmacol Ther. 2010;23(4):257-267.

40. Ágh T, Inotai A, Mészáros Á. Factors associated with medication adherence in patients with chronic obstructive pulmonary disease. Respiration. 2011;82(4):328-334.
International Journal of COPD

\section{Publish your work in this journal}

The International Journal of COPD is an international, peer-reviewed journal of therapeutics and pharmacology focusing on concise rapid reporting of clinical studies and reviews in COPD. Special focus is given to the pathophysiological processes underlying the disease, intervention programs, patient focused education, and self management protocols.

\section{Dovepress}

This journal is indexed on PubMed Central, MedLine and CAS. The manuscript management system is completely online and includes a very quick and fair peer-review system, which is all easy to use. Visit http://www.dovepress.com/testimonials.php to read real quotes from published authors. 